\title{
WCZESNONEOLITYCZNE FIGURKI ANTROPOMORFICZNE NA PRZYKLADZIE NOWEGO ZNALEZISKA $Z$ LIPNICY W WOJEWÓDZTWIE WIELKOPOLSKIM
}

\author{
EARLY NEOLITHIC ANTHROPOMORPHIC FIGURINES. \\ A NEW DISCOVERY AT LIPNICA, WIELKOPOLSKA VOIVODESHIP
}

\section{Andrzej Krzyszowski}

Muzeum Archeologiczne

ul. Wodna 27,61-781 Poznań, Poland

\begin{abstract}
A fragment of clay figurine was found in a Band Pottery Culture pit at Lipnica near Szamotuly during rescue excavations of the Yamal gas pipe (1996). It was probably painted and ornamented by vertically incised lines. Its compositional and formal attributes make us believe that this is a fragment of anthropomorphic, freestanding and realistically represented figurine without steatopygic features. It was either an early Neolithic idol or toy. The figurine shows similarities to alike artifacts from Central European oecumene of the Band Pottery culture (in particular in the Lower Silesia and Germany), which are characterized by their slenderness and incised ornamentation. Additionally, the painting decoration is indicative of influences from south-eastern centers of the LBK (Ukraine and Moravia).
\end{abstract}

\section{UWAGI WSTĘPNE}

W trakcie badań wykopaliskowych prowadzonych przez autora (z ramienia ONK PKZ Sp. z o.o.) jesienią 1996 r. na stanowisku nr 21 w Lipnicy koło Szamotuł, na trasie gazociagu tranzytowego, odkryto fragmenty wykonanej z gliny figurki, przedstawiającej pierwotnie postać ludzką, datowaną wstępnie na okres wczesnego neolitu. To interesujące i rzadkie na ziemiach polskich znalezisko, odkryto w jednej z jam, którą na podstawie ceramiki przyporządkowano do pozostałości ludności kultury ceramiki wstęgowej rytej (KCWR), z jej tzw. fazy nutowej.

Fizjograficznie stanowisko to zajmuje obszar małej, aczkolwiek dobrze wykształconej doliny, a w jej ramach północny stok i krawędź. Dno tej doliny wypełnia nadto bezimienny ciek, a bezpośrednio przy stanowisku występuje niewielkie oczko wodne (ryc. 1). Gleba należy do urodzajnych (tzw. III klasy bonitacyjnej) i strukturalnie przypomina czarne ziemie kujawskie. 


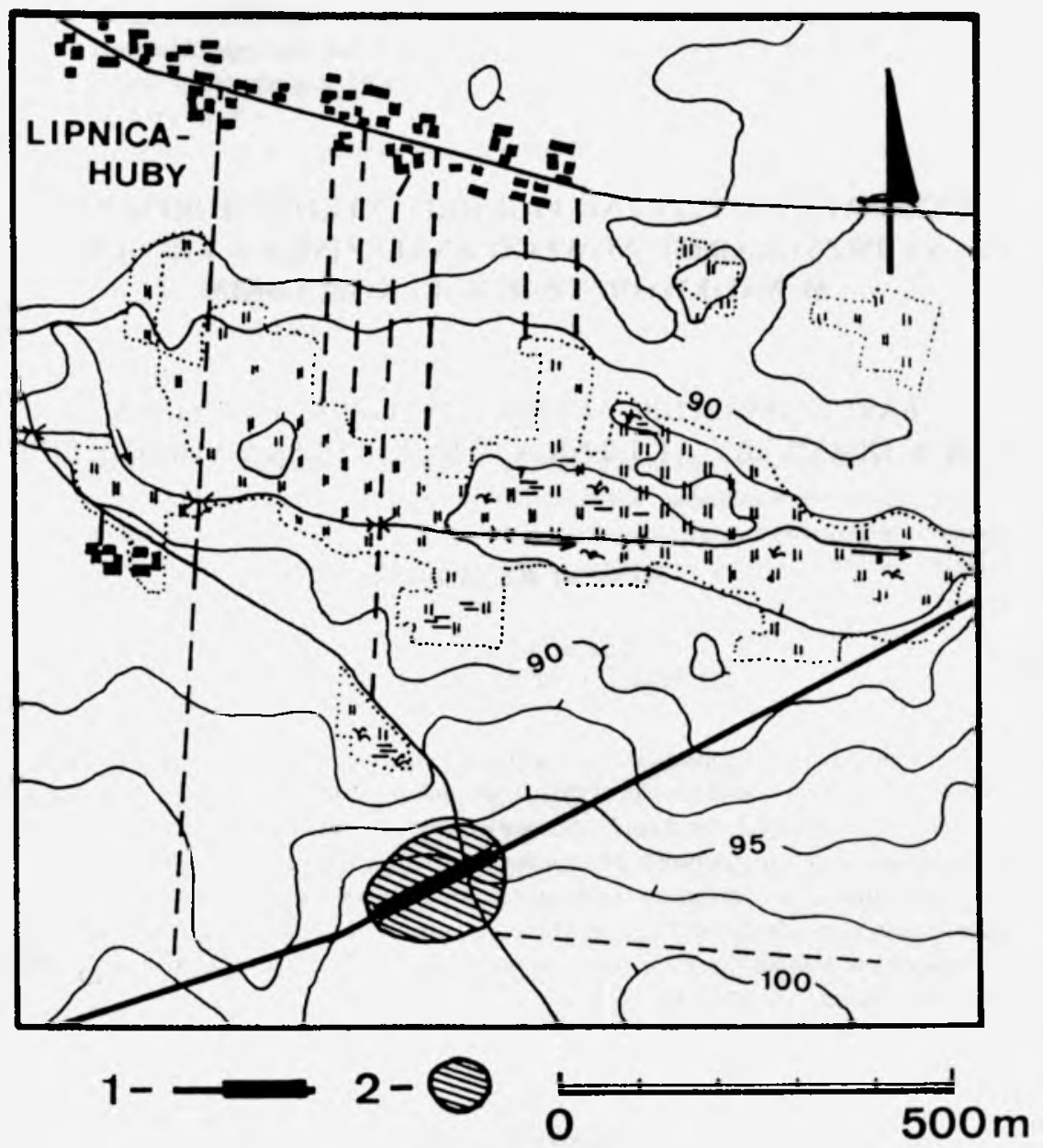

Ryc. I. Lipnica, gm. Szamotuły, woj. wielkopolskie, stan. 21. Lokalizacja stanowiska: 1 - trasa gazociagu; pogrubioną linią zaznaczono wykop archeologiczny, 2 - zasięg stanowiska (rys. A. Krzyszowski)

Abb. 1. Lipnica, Gem. Szamotuły, Woi. Wielkopolskie, Fst. 21. Lage des Fundplatzes: 1 - Gastrasse; die starke Linie markiert die Grabungsfläche; 2 - Ausdehnung des Fundplatzes (Zeichn. A. Krzyszowski)

Badaniami wykopaliskowymi na tym stanowisku objęto obszar o powierzchni $2660 \mathrm{~m}^{2}$, odkrywając łącznie 111 obiektów nieruchomych reprezentujących trzy horyzonty kulturowo-chronologiczne: kulturę ceramiki wstęgowej rytej, kulturę łużycką i kulturę pomorską (ryc. 2). W tej grupie 13 obiektów reprezentuje pozostałości osadnictwa ludności kultury ceramiki wstęgowej rytej. Funkcjonalnie wśród obiektów KCWR wyróżniono 8 jam, z których dwie mają prawdopodobnie charakter mieszkalny (obiekt 22 i 23), a 5 określono jako dołki posłupowe (obiekty 26, 35, 36, 37 , 38 i 39). 


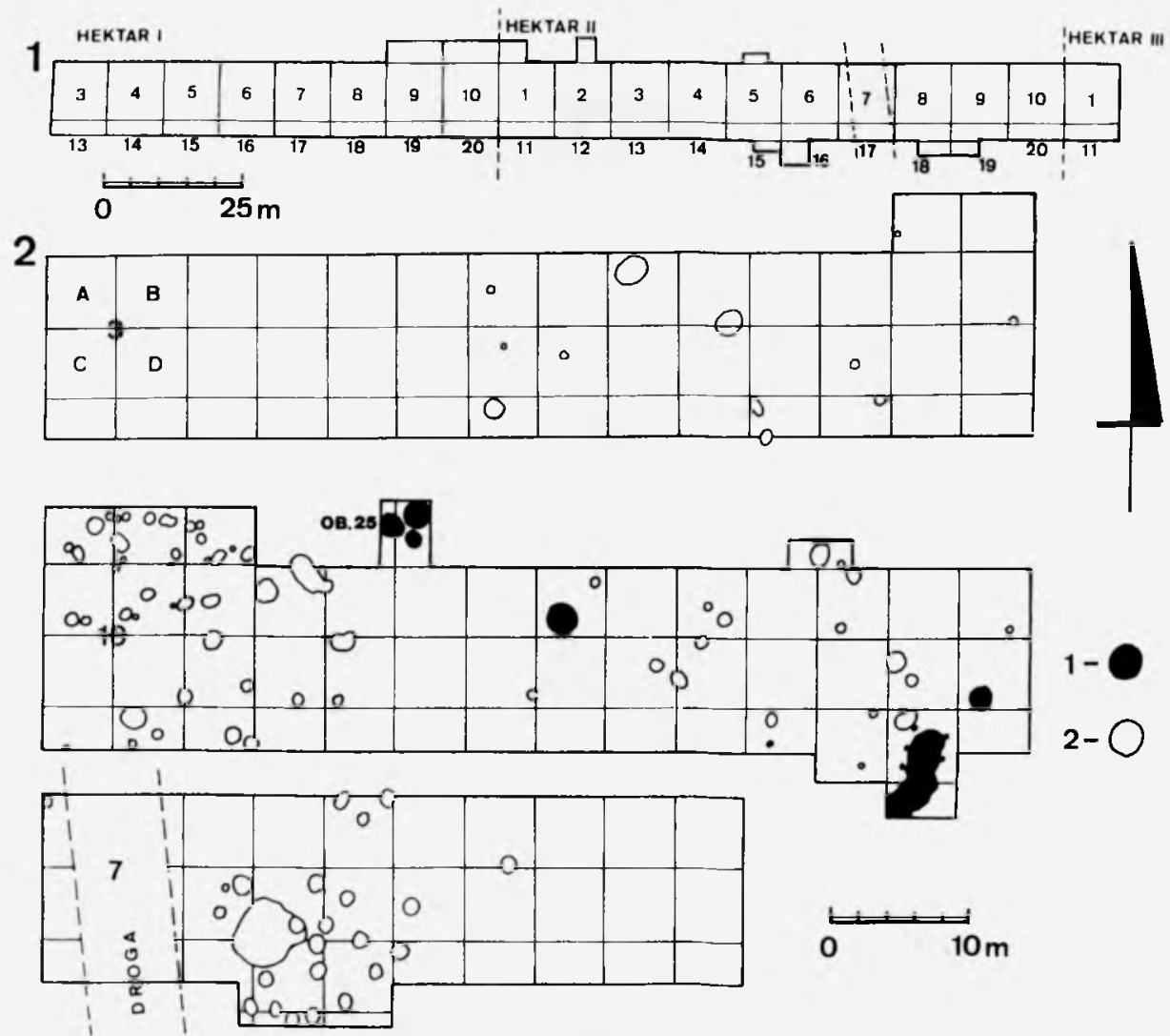

Ryc. 2. Lipnica, gm. Szamotuły, woj. wielkopolskie, stan. 21. Plan wykopu archeologicznego (1) wraz z rozmieszczeniem obiektów nieruchomych (2): 1 - obiekty KCWR, 2 - obiekty kultury łużyckiej i pomorskiej (rys. A. Krzyszowski)

Abb. 2. Lipnica, Gem. Szamotuły, Woi. Wielkopolskie, Fst. 21. Grabungsplan (1) mit der Verteilung der Befunde (2): 1 - Befunde der Linienbandkeramik, 2 - Befunde der Lausitzer und der Pommerschen Kultur (Zeichn. A. Krzyszowski)

Szczególnie interesującym obiektem tej kultury okazała się jama (odpadkowa), oznaczona jako obiekt 25. W jej wypełnisku znaleziono fragmenty analizowanej figurki. Obiekt był usytuowany w środkowej części wykopu i wystapił w bezpośrednim sąsiedztwie dwóch innych jam KCWR ( $\mathrm{nr} 40$ i 41 ).

Zarys obiektu 25 ukazał się na głębokości $42 \mathrm{~cm}$ od współczesnej powierzchni gruntu i miał kształt lekko owalny, o wymiarach $184 \times 160 \mathrm{~cm}$ (ryc. 3). Na poziomie stropu treść kulturową tworzył ciemnoszary, lekko gliniasty piasek, z udziałem pierwotnej próchnicy. W partii centralnej wypełnisko zmieniło się w czarny, lekko gliniasty piasek z udziałem spalenizny i pierwotnej próchnicy o głębokości około $38 \mathrm{~cm}$. W tej ostatniej $\mathrm{z}$ opisanych warstw wystapiło prawie $90 \%$ ruchomego materiału zabytkowego, w tym fragmenty figurki. Poniżej zalegała dość cienka warstwa $(10-12 \mathrm{~cm})$ jasnoszarego i bar- 

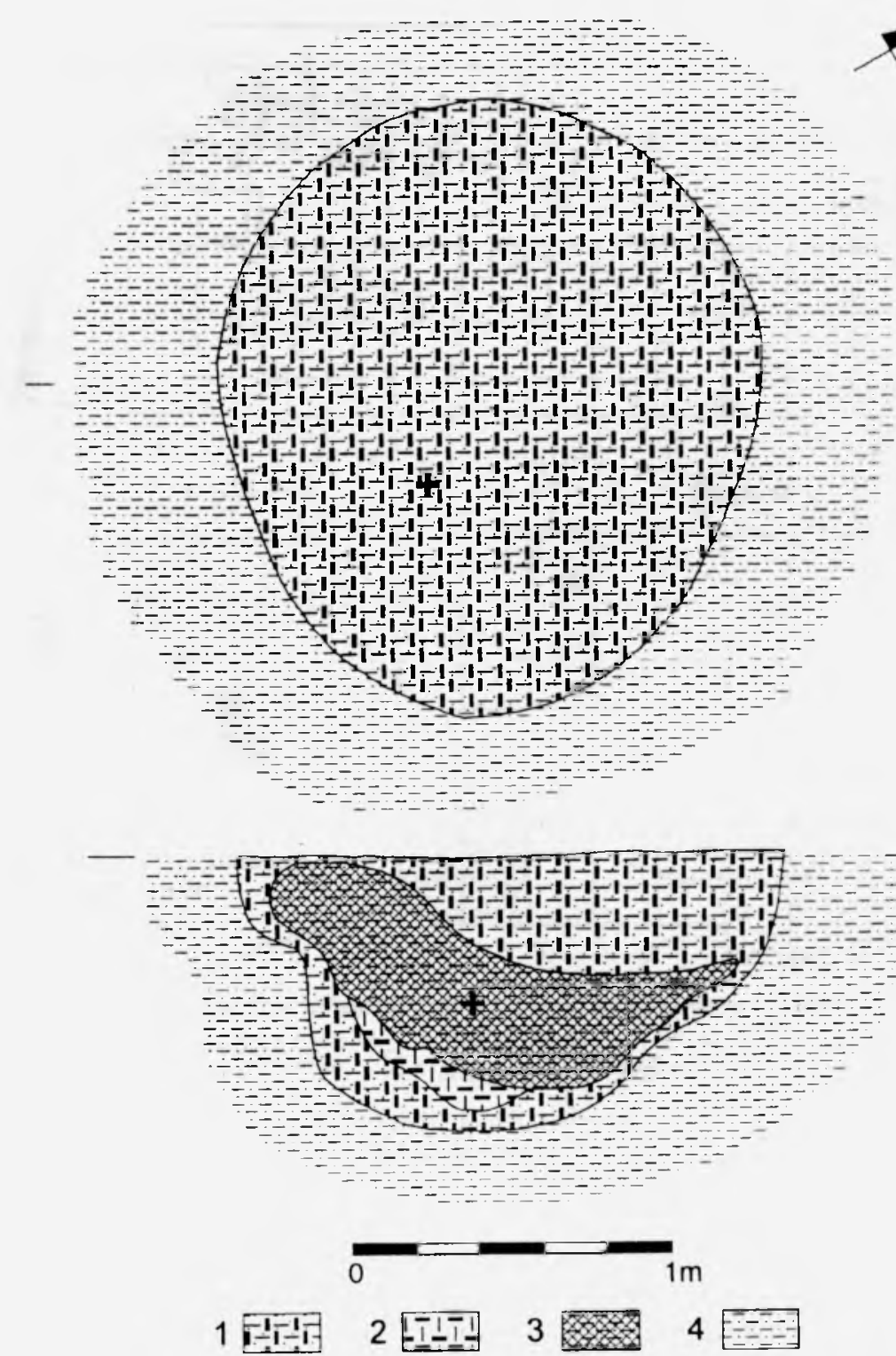

Ryc. 3. Lipnica, gm. Szamotuly, woj. wielkopolskie, stan. 21. Rzut poziomy i profil jamy KCWR (obiekt 25): l - ciemnoszary, lekko gliniasty piasek, 2 - jasnoszary, bardzo mocno gliniasty piasek, 3 - czarny, lekko gliniasty piasek z udziałem spalenizny, 4 - ciemno-żólto-brązowa surowa glina, lekko spiaszczona; krzyżykiem oznaczono miejsce znalezienia figurki (rys. J. Sawicka i W. Kudra)

Abb. 3. Lipnica, Gem. Szamotuly, Woi. Wielkopolskie, Fst. 21. Planum und Profil der linienbandkeramischen Grube (Objekt 25): 1 - dunkelgrauer, leicht lehmiger Sand, 2 - hellgrauer stark lehmiger Sand, 3 - schwarzer, leicht lehmiger Sand mit Brandspuren; 4 - ocker-brâunlicher Lehm, leicht sandig. Mit einem Kreuz ist die Position des Figürchens markiert (Zeichn. J. Sawicka u. W. Kudra) 
dzo mocno gliniastego piasku, pozbawionego udziału pierwotnej próchnicy i przechodzacego ponownie w partii spagowej w szary i ciemnoszary lekko gliniasty piasek. Calkowita głębokość tego obiektu wynosiła $82 \mathrm{~cm}$, a jego kształt był zbliżony do nieckowatego. Calec tworzyła $z$ kolei ciemno-żółto-brązowa i lekko spiaszczona glina

$Z$ obiektu wydobyto 207 fragmentów ceramiki, z których część udało się zrekonstruować (por. ryc. 6,7), 7 przedmiotów krzemiennych, 10 grudek polepy oraz nieliczne i drobne fragmenty kości zwierzęcych. Gliniana figurka została znaleziona w czterech ulamkach, które zalegały w środkowej części jamy, na głębokości $0,88 \mathrm{~m}$ od współczesnego poziomu ziemi (ryc. 3).

\section{ANALIZA FORMALNA}

Na pozostałości figurki składają się cztery ułamki, które po rekonstrukcji tworzą dwie kończyny dolne, najprawdopodobniej postaci ludzkiej. Jedna $\mathrm{z}$ nich, zachowana w całości, ma wymodelowaną stopę, której palce zaznaczono za pomocą trzech wyraźnych nacięć, wykonanych od spodu. Kończyna ta, podobnie jak ułamek drugiej, ma identycznie uformowane kolana, zaakcentowane zgrubieniami w części frontalnej. Kolana są ponadto zaznaczone proporcjonalnie w stosunku do całej długości nóg. Fragment nogi z zachowaną stopą nie ma natomiast wymodelowanych kostek.

Kończyna dolna prawa jest całkowicie zachowana (od stopy do biodra) i ma długość $10,1 \mathrm{~cm}$. Jej średnica na wysokości uda wynosi $2,0 \mathrm{~cm}$, zaś na wysokości piszczela $1,8 \mathrm{~cm}$, długość stopy liczy $3,1 \mathrm{~cm}$, a jej szerokość $1,8 \mathrm{~cm}$ (ryc. $4: 1$ ).

Fragment lewej kończyny dolnej, z zachowaną tylko częścią goleniową, ma dlugość $5,3 \mathrm{~cm}$, co stanowi zapewne około $1 / 2$ jej pierwotnej długości. Średnica powyżej kolana wynosi $2,2 \mathrm{~cm}$, natomiast poniżej kolana waha się w granicach 1,8-2,0 cm (ryc. 4:2).

Obie części figurki były prawdopodobnie malowane, i to być może na całej powierzchni. Zachowały się jedynie nieliczne, drobne ślady farby (?) (na ryc. 4:1-2 - zaznaczono je czarną szrafurą), wymagające specjalistycznej weryfikacji. Ponadto obie nogi figurki są zdobione pionowo rytymi żłobkami, zlokalizowanymi na ich bocznych powierzchniach: na jednej - na części udowej (ryc. 4:1), na drugiej - na części goleniowej (ryc. 4:2).

Figurka w przełomie i na powierzchni zewnętrznej jest barwy jasnożółtej, a jedynie wewnątrz ma zabarwienie szare, będące zapewne skutkiem działania odmiennych temperatur podczas wypału. Na powierzchni zewnętrznej zachowaly się miejscami ślady ziemistej patyny, powstałej prawdopodobnie po wytarciu się farby, którą nałożono przypuszczalnie dopiero po wypale przedmiotu. Powierzchnie są lekko szorstkie, bez połysku. Glina, której użyto jako tworzywa jest miałka, dość tłusta, starannie wyrobiona, miejscami schudzona domieszką mineralną w postaci drobnoziarnistego thucznia i piasku, choć spotyka się też pojedynczo gruboziarnisty tłuczeń o średnicy ziaren nawet ponad $4 \mathrm{~mm}$. Przyjmując, iż długość zachowanej nogi wynosiła około $10 \mathrm{~cm}$ można założyć, że pierwotna wysokość figurki miała $20-23 \mathrm{~cm}$ (ryc. 5). Figurkę ulepiono za- 

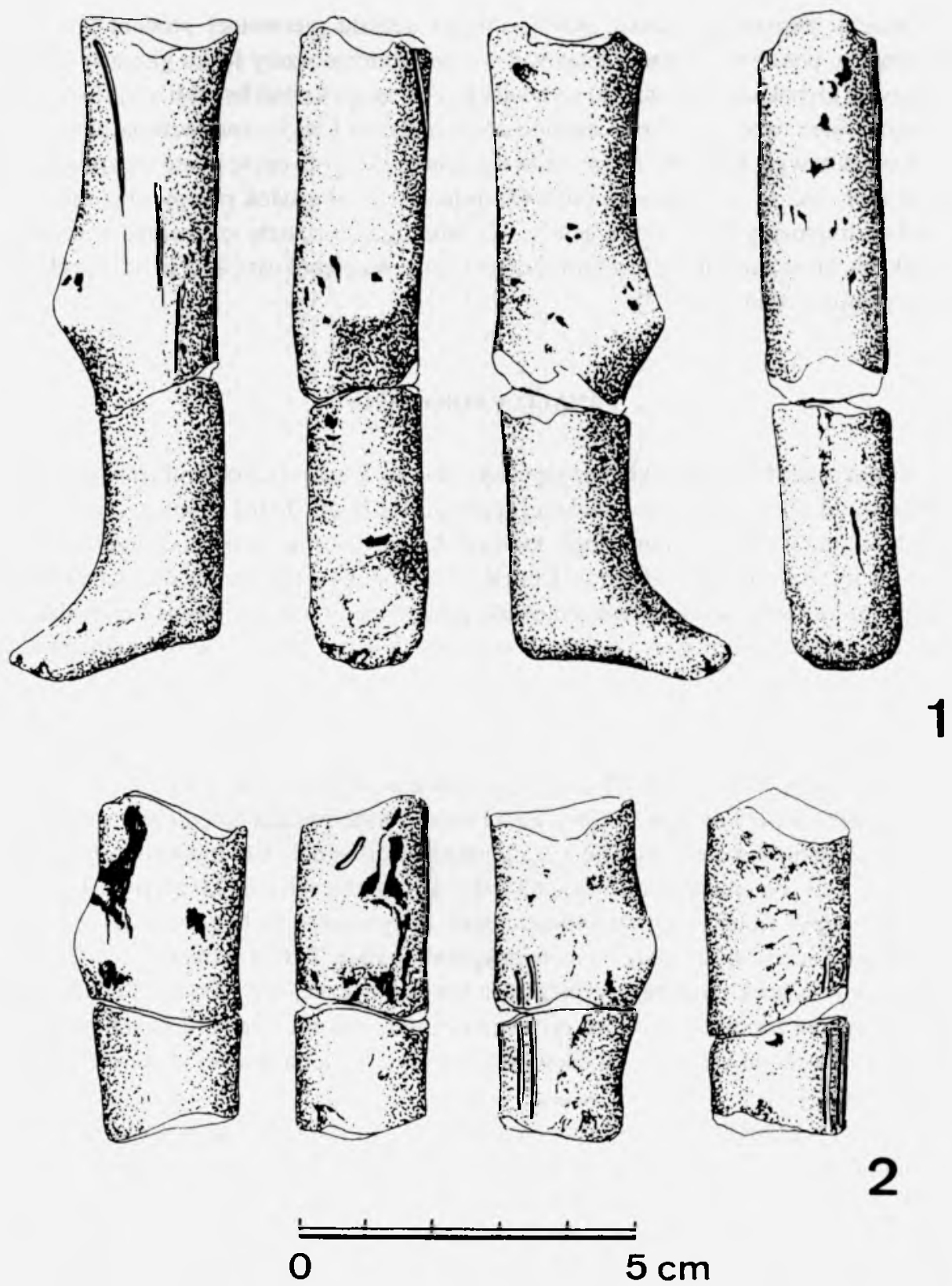

Ryc. 4. Lipnica, gm. Szamotuły, woj. wielkopolskie, stan. 21. Fragmenty figurki glinianej: 1 - kończyna prawa, 2 - fragment kończyny lewej (rys. J. Sawicka)

Abb. 4. Lipnica, Gem. Szamotuły, Woi. Wielkopolskie, Fst. 21. Fragmente des Tonfigürchens: 1 -rechte Extremităt; 2 - linke Extremität (Zeichn. J. Sawicka) 


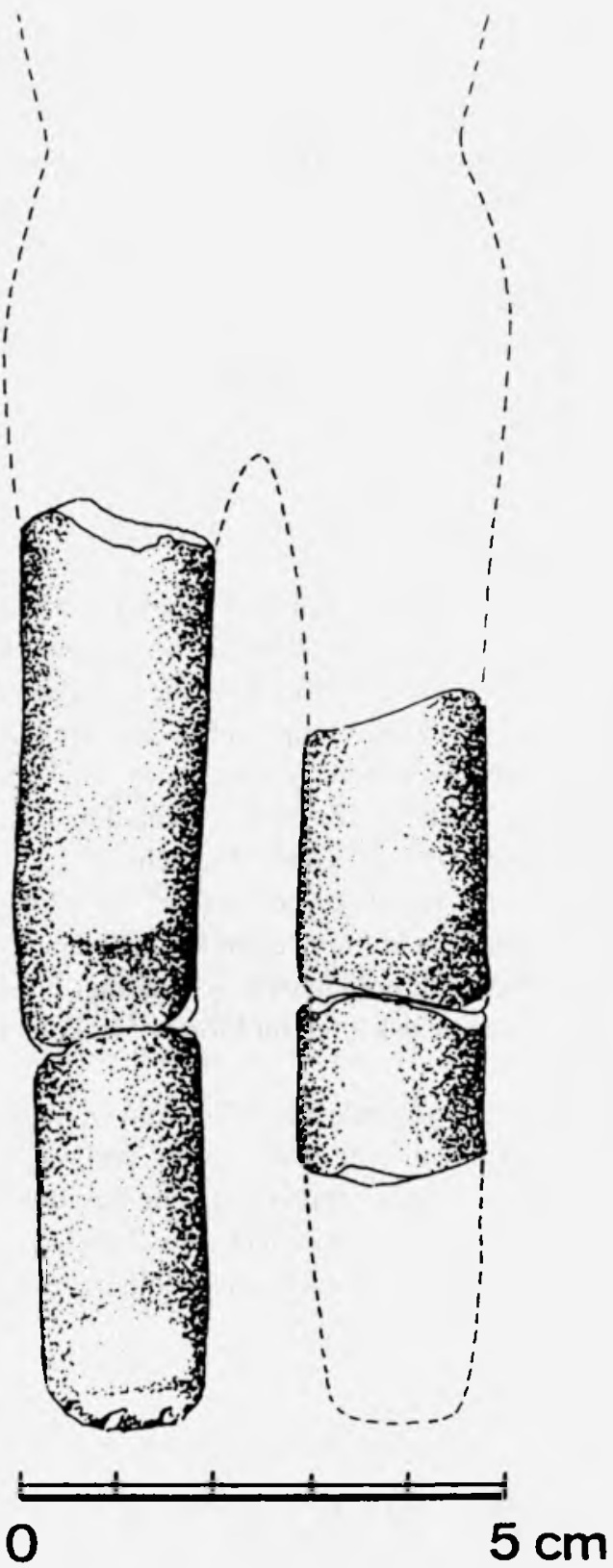

Ryc. 5. Lipnica, gm. Szamotuły, woj. wielkopolskie, stan. 21. Rekonstrukcja figurki (rys. J. Sawicka) Abb. 5. Lipnica, Gem. Szamotuły, Woi. Wielkopolskie, Fst. 21. Rekonstruktion des Figürchens (Zeichn. J. Sawicka) 
pewne z kilku kawałków surowca. Przedmiot ten został rozbity jeszcze w czasach pierwotnych, o czym można wnioskować po skorodowanych przełomach.

Rekonstrukcja całej figurki nie jest możliwa. Nie ulega jednak wątpliwości, że realistycznie wymodelowano obie nogi, w tym kolana i stopę z palcami, zamarkowanymi nacięciami. Zdaje się, że chodzi o pierwotnie pełnoplastyczną i wolno stojącą figurkę postaci ludzkiej, której nogi są lekko rozstawione i mają płaskie stopy. Kształt innych partii figurki (korpus, głowa i ręce) można jedynie hipotetycznie sugerować na podstawie analizy porównawczej (por. niżej). Niemniej z zachowanych pozostałości figurki można wnosić, iż wytwór ten reprezentuje dość wysoki poziom pod względem plastycznego oddania anatomicznych cech ciała ludzkiego.

\section{ANALIZA PORÓWNAWCZA}

Obecnie spróbujemy określić miejsce figurki z Lipnicy w zbiorze wytworów podobnych znalezisk przypisanych KCWR i kulturze wstęgowej kłutej (KCWK), pochodzących przede wszystkim z terenu Polski. Kwestię tę rozpatrzymy na płaszczyźnie kompozycyjnoformalnej i tematycznej, biorąc pod uwagę, nieliczne jak dotąd odnośne znaleziska figurek i ich fragmentów w obrębie inwentarzy obu kultur wstęgowych (m.in. z Głogowa-Nosocic ${ }^{1}$, Strzelina ${ }^{2}$, Starego Zamku ${ }^{7}$ - woj. dolnośląskie, Raciborza-Ocic ${ }^{4}$ - woj. śląskie, Nowej Huty-Pleszowa ${ }^{5}$ Jaskini Wierzchowskiej, ${ }^{6}$ Ojcowa $^{7}$ - woj. małopolskie, Przybranowa - woj. kujawsko-pomorskie ${ }^{8}$, ze Zlotej - woj. świętokrzyskie $^{9}$ ) czy też z zasobów ukraińskiej kultury ceramiki malowanej (trypolskiej), ujawnionych na przedwojennych obszarach południowo-wschodniej Polski ${ }^{10}$. Odwołujemy się też do znacznie liczniejszych znalezisk z terenu Moraw ${ }^{11} \mathrm{i}$ z kolei nielicznych z obszaru Niemiec ${ }^{12}$.

Z przeglądu figurek, a raczej wyłącznie ich uszkodzonych fragmentów pochodzących z ziem polskich, wynika, że są to realizacje zróżnicowane pod względem kształtu, wielkości i stopnia schematyzacji. Generalnie reprezentują one typ idoli steatopygicznych. Na ich tle pozostałości figurki z Lipnicy, mimo ułamkowości zachowania, wyróżniają się jak się wydaje - dość realistycznym potraktowaniem dolnej części przedstawionej posta-

\footnotetext{
I Seger 1916, s. 15 , ryc. 52.

${ }^{2}$ Wojciechowski, Cholewa 1995 , s. 158-161, ryc. 8, tabl. IIlf.

${ }^{3}$ Romanow 1977 , ryc. 20.

${ }^{4}$ Seger 1916 , s. 8 , ryc. 21 ; Jank owska, Wojciechowska 1973 , ryc. 6 b.

${ }^{5}$ Godlowska 1964, ryc. 14e; Rachwaniec 1976, ryc. 1, 2.

${ }^{6}$ Kostrzewski 1948, s. 136, tabl. 53:5.

${ }^{7}$ Rook 1980 , s. 39 , ryc. 8 a, b.

${ }^{8}$ Czerniak 1994, s. 51, ryc. 14:13.

${ }^{9}$ Podborský 1985, tabi. IX:5.

${ }^{10}$ Cehak 1933, s. 166-193; Majewski 1938, s. 64-86.

${ }^{11}$ Podborský 1985, s. 21-191.

${ }^{12} \mathrm{Höckmann} 1965$, s. $1-34$; K a u fm ann 1976 , s. $78-80$.
} 
ci. Można nawet stwierdzić, iż okaz lipnicki nie mieści się w konwencji realizowanej przez ludność kultury ceramiki wstęgowej rytej na terenie jej polskiej ekumeny. Nogi są bowiem opracowywane w KCWR czy KCWK z reguły schematycznie i mają najczęściej kształt stoźka, szerokiego w biodrach i zwężającego się ku dołowi lub są zwarte i jedynie oddzielone bruzda, ale wówczas najczęściej z uwydatnieniem steatopygicznych pośladków ${ }^{13}$. W figurce z Lipnicy - dzięki układowi górnej części nogi - nie można się spodziewać silnego zaakcentowania bioder $\mathrm{i}$ - co za tym idzie - nadmiernego uwydatnienia pośladka.

Schematyzacja modelunku dolnych partii figurek KCWR postępowała w kierunku lączenia obu nóg. Ta tendencja doprowadziła w końcu do zgrubienia dolnej partii postaci, tak samo szerokiego, jak tułów. Przejście ze stylu ,realistycznego”, do jakiego zaliczamy okaz z Lipnicy, do typu ,schematyczno-naturalistycznego" i dalej ,geometrycznego" ma swoją sekwencję chronologiczną. "Realizm" uznaje się bowiem powszechnie za zjawisko starsze w ciągu typologicznym od figurek wykonanych schematycznie, choć oba te nurty rozwijały się chyba przez pewien czas równolegle ${ }^{14}$.

Konkludując tę część analizy można stwierdzić, że figurka z Lipnicy jest przykładem figurki wolno stojącej, wykonanej w stylu, ,realistycznym", o nogach modelowanych oddzielnie i prawdopodobnie dość dużej (ok. 20-23 cm) oraz starannie wykonanej i dekorowanej ornamentem rytym i może malowanej farbą. Rekonstruowana jej pierwotna wielkość odpowiada niektórym calkowicie zachowanym figurkom, na przykład egzemplarzowi z Koszylowiec na Ukrainie, o wysokości $24,7 \mathrm{~cm}^{15}$, z obszaru kultury trypolskiej. Także długość jednej z nóg figurki z Lipnicy odpowiada wielkościom odpowiedników ze stanowisk tej kultury na Ukrainie, na przykład nogi figurki z Koszyłowiec, o długości $11,6 \mathrm{~cm}$ i $8,7 \mathrm{~cm}^{16}$, czy też z pokrewnej jej kultury na Morawach, na przykład fragmentów nóg z miejscowości Střelice ${ }^{17}$, o długości 8,2 i 7,8 cm. Znamy zarówno analogie modelunku kolan $^{18}$, jak i palców u stóp, zaznaczonych nacięciami ${ }^{19}$.

Czy równie realistycznie wykonane były pozostałe części omawianej figurki - trudno powiedzieć. Generalnie zaprzecza temu stylistyka dotąd znanych figurek kultur wstęgowych z ziem polskich, ponieważ zarówno głowa, jak i ręce były z reguły wykonane w sposób schematyczny; wyjątki są bardzo nieliczne ${ }^{20}$. Podobną uwagę można odnieść także do znalezisk $z$ terenu Moraw ${ }^{2 !}$.

W przypadku ewentualnego malowania, analizowana figurka z Lipnicy znajduje szereg analogii przede wszystkim w zasięgu kultury ceramiki malowanej na

${ }^{13}$ Seger 1916 , s. 8, ryc. 21, s. 15, ryc. 52; Cehak 1933, np. tabl. I:1, 3, 5, Ill:3; V:7; M a jew ski 1938, ryc. $1,2,6,7,21$.

${ }^{14}$ Cehak 1933, s. 190-193; M ajew ski 1947, s. 107-110; 1971, s. 28-31; Marešová 1971, s. 70-72; Podborsky 1985, tabl. IV).

${ }^{15}$ Cehak 1933, tabl. 1:1.

${ }^{16}$ Cehak 1933, tabl. VIII:7, 9.

${ }^{17}$ Marešová 1971, tabl. XVI:7, 8.

${ }^{18}$ Np. Cehak 1933, tabl. 1:1; Marě̌ová 1971, tabl. XVI:8.

${ }^{19}$ Np. Cehak 1933, tabl. 11:7, 8; Baumann 1976, ryc. 4a.

${ }^{20}$ Cehak 1933, tabl. Ill:4.

${ }^{21}$ Marešová 1971, tabl. I-II, IV-XVII; Podborský 1985, tabl. 1-117. 
Ukrainie $^{22}$ czy też morawskiej ceramiki malowanej, gdzie, jak podaje Podborský ${ }^{23}$, malowane figurki stanowią około $10 \%$ całości zbioru. Malowanie, najczęściej czerwoną i żółtą farbą lub ochrą, obejmowało tam całą powierzchnię figurki, o co podejrzewamy właśnie okaz z Lipnicy. Kolejnym elementem dekoracji, występującym na figurkach „wstęgowych" - zanotowanym również na okazie z Lipnicy - jest rycie żłobków lub wyciskanie kropek ${ }^{24}$. Ornament ryty pokrywa zarówno całą powierzchnię figurek lub poszczególne części ciała, a więc nogi czy ręce. Bardzo zbliżony do lipnickiego ryty ornament mają nogi figurek $\mathrm{z}$ terenu Niemiec ${ }^{25}$.

Dekorowanie figurek ornamentem malowanym lub rytym bywa uważane przez niektórych badaczy za kryterium identyfikacji płci. Mianowicie brak tej cechy lub rzadkie występowanie odnosi się do figurek męskich, choć i tu spotyka się wyjątki ${ }^{26}$. Przyjmuje się również, iż postacie męskie były przedstawiane z reguły w postawie stojącej. Akceptując powyższe uwagi można by przypuszczać, że większość cech analizowanej figurki wskazuje na to, że mamy do czynienia z wyobrażeniem postaci męskiej. Na podstawie obserwacji cech plastyki figuralnej południowo-wschodniej Europy, objętej w dobie wczesnego i środkowego neolitu zasięgiem szeroko pojętych kultur „wstęgowych”, jestem jednak przeciwnego zdania. Tamtejszy główny typ przedstawień figuralnych to naga postać kobieca, typ wiązany najczęściej z etosem neolitycznej bogini. Idea ta, ukształtowana w bliskowschodnich centrach cywilizacyjnych, przeszła w trakcie swego rozprzestrzenienia się na terenach ościennych także swoistą ewolucję morfologiczną. Zjawisko to, dotyczące również ziem polskich, objętych zasięgiem kultur cyklu naddunajskiego (wstęgowego), ukazuje narastająca tendencja do wysmuklania figurek, przeciwna do silnego z reguły akcentowania masy ciała w plastyce krajów śródziemnomorskich. Zdaniem niektórych autorów miałoby to odzwierciedlać zróżnicowania fizycznoantropologiczne ludów zamieszkujących „wstęgowa” ekumenę ${ }^{27}$. Fragment figurki z Lipnicy dobrze wplata się - jak sądzę - w wyżej zasygnalizowane tendencje. Mimo braku ścisłych analogii do tej figurki wydaje się ona jednak bliższa konwencjom przedstawień figuralnych stosowanym na terenie środkowoeuropejskiej (Dolny Śląsk, Niemcy) ekumeny kultur wstęgowych (tendencja do wysmuklania postaci, rycie ornamentu), jednakże przez fakt prawdopodobnego malowania, okaz ten odzwierciedlałby także impulsy z centrów południowo-wschodnich cyklu „wstęgowego” (Ukraina, Morawy).

Także jego funkcja, jako prawdopodobnie wczesnoneolitycznego idola, wydaje się nie budzić wątpliwości ${ }^{28}$, choć oczywiście nie można wykluczyć również prozaicznej funkcji typu utylitarnego (zabawka?).

\footnotetext{
${ }^{22}$ Cehak 1933, s. 180-183, tabl. II:I, III:1, V:3.

${ }^{23}$ Podborský 1985, s. 92.

${ }^{24} \mathrm{~Np}$. Seger 1916, ryc. 21, 52; H ö c km a n n 1965, ryc. 1:1, 3, 4, 7, 9, 2:1, 4, 5, 3:6, 4:1, 3, 4, 5:1, 3, 5, 6, 8, $6: 1,2$; Kaufmann 1976, ryc. 3h; Czerniak 1994, ryc. 14:13.

${ }^{25} \mathrm{Höckmann} 1965$, ryc. 5:5, 8; K aufmann 1976, ryc. 3b, c.

${ }^{26}$ C ehak 1933, s. 187 , tabl. VIII:6.

${ }^{27}$ Cehak 1933, s. 191; Gleń, Kaczanowski 1976, s. 77-78; Podborský 1985, s. 95n.

${ }^{28}$ Cehak 1933, s. 228-235; Majewski 1938, s. 63-86; Jankowska, Wojciechowska 1973, s. 117-131; Podborský 1985, s. 149-166; por. także Gediga 1970, s. 174-229.
} 
Z kolei fakt pierwotnego ,pokawałkowania” tego typu figurek jest interpretowany w literaturze przedmiotu jako zabieg intencjonalny, związany najczęściej z obrzędowością sepulkralną ${ }^{29}$. Częściowo tylko zbadana osada w Lipnicy nie pozwala odnieść się do tej hipotezy.

\section{WNIOSKI}

Odkryty w Lipnicy koło Szamotuł wczesnoneolityczny ceramiczny wytwór plastyczny - na podstawie przeprowadzonej analizy morfologicznej i porównawczej $\mathrm{z}$ dużym prawdopodobieństwem można zakwalifikować do pełnoplastycznej rzeźby, przedstawiającej w sposób realistyczny idola, zapewne żeńskiego. Byłoby to pierwsze tego rodzaju znalezisko zasobów kultury ceramiki wstęgowej rytej na terenie Wielkopolski. Jej stanowiska coraz liczniej odkrywane ostatnio na terenie tego makroregionu (np. Racot, stan. 18 i 25$)^{30}$, w tym również w ramach badań archeologicznych na gazociągu jamalskim (m.in. Otorowo, stan. 41: badania M. Wróbla w 1995-1996 r.; Otorowo, stan. 66: badania A. Krzyszowskiego w 1995-1996 r.; Kowalewko, stan. 12 i 13 : badania T. Skorupki w 1996-1997 r. czy Brodziszewo, stan. 5 i 35: badania T. Laszkiewicza i A. Stempin w 1995 r. $)^{31}$, kreślą dość zwartą i dynamiczną ekumenę, która kontynuowała model kultury materialnej i duchowej, przyniesiony $z$ obszarów macierzystych (naddunajskich). Datowanie części tych zespołów (są jeszcze w trakcie opracowywania) odnosi się, co jest szczególnie interesujące, również do tzw. fazy nutowej (Otorowo, stan. 66), a więc dość wczesnej w rozwoju tej kultury na Niżu Polskim. Podobnie można określić chronologicznie kilkanaście obiektów nieruchomych $\mathrm{z}$ analizowanej osady w Lipnicy. Szczegółową chronologię tego stanowiska opieramy na zbiorze około 500 fragmentów ceramiki naczyniowej, wśród których 207 (ryc. 6, 7) pochodzi z analizowanego obiektu 25 , zawierającego przedmiotową figurkę antropomorficzną.

Pewną wskazówką chronologiczna, prócz cech stylistyki ceramiki naczyniowej, jest morfologia dolnej partii figurki (por. wyżej), wplatająca się w rozwój plastyki figuralnej „wstęgowców”, biegnąca w kierunku zaniku modelowania każdej nogi z osobna. Figurka lipnicka wykazuje więc cechy starszych realizacji, co potwierdzają również ustalenia w tym zakresie dokonane dla terenów morawskich ${ }^{32}$.

${ }^{29}$ Majewski 1947, s. 104n.; 1971, s. 13, 14.

30 „Informator Archeologiczny” 1985, s. 33; 1986, s. 30; 1987, s. 41.

${ }^{31}$ Dziękuję za przekazane informacje autorom tych badań: M. Wróblowi, T. Skorupce, T. Łaszkiewiczowi i A. Stempin.

${ }^{32}$ Marešová 1971, s. 7-72; Podborský 1985, tabl. IV. 

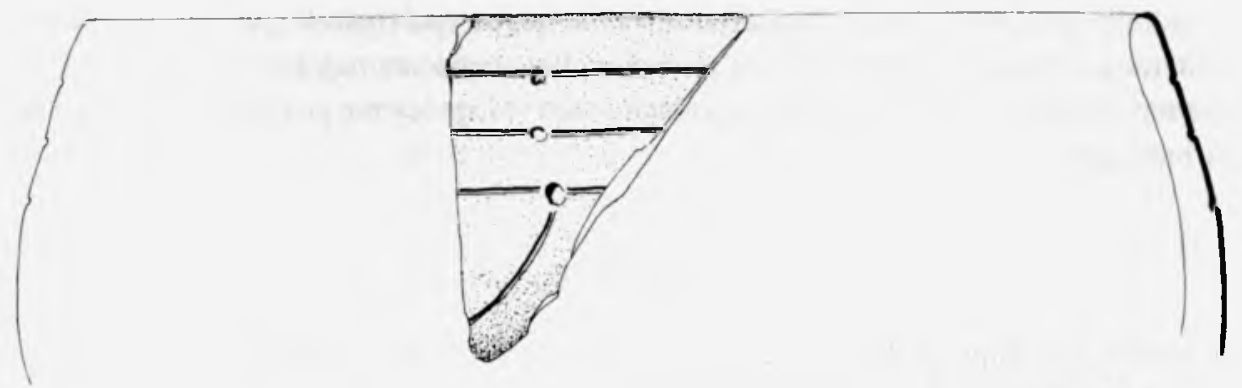

1
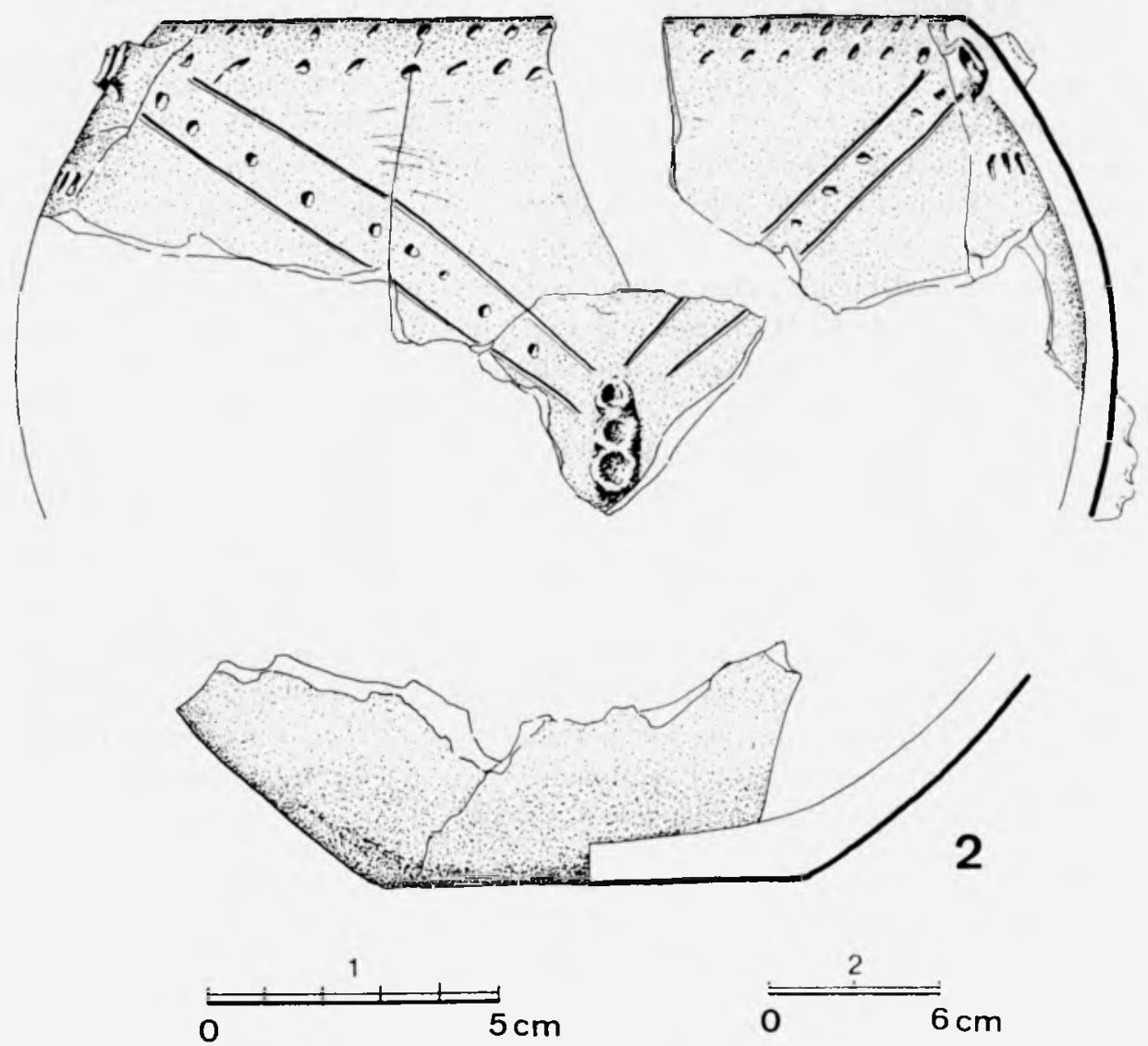

Ryc. 6. Lipnica, gm. Szamotuły, woj. wielkopolskie, stan. 21. Wybór ceramiki z obiektu 25 (rys. J. Sawicka) Abb. 6. Lipnica, Gem. Szamotuły, Woi. Wielkopolskie, Fst. 21. Keramikauswahl aus Objekt 25 (Zeichn. J. Sawicka) 

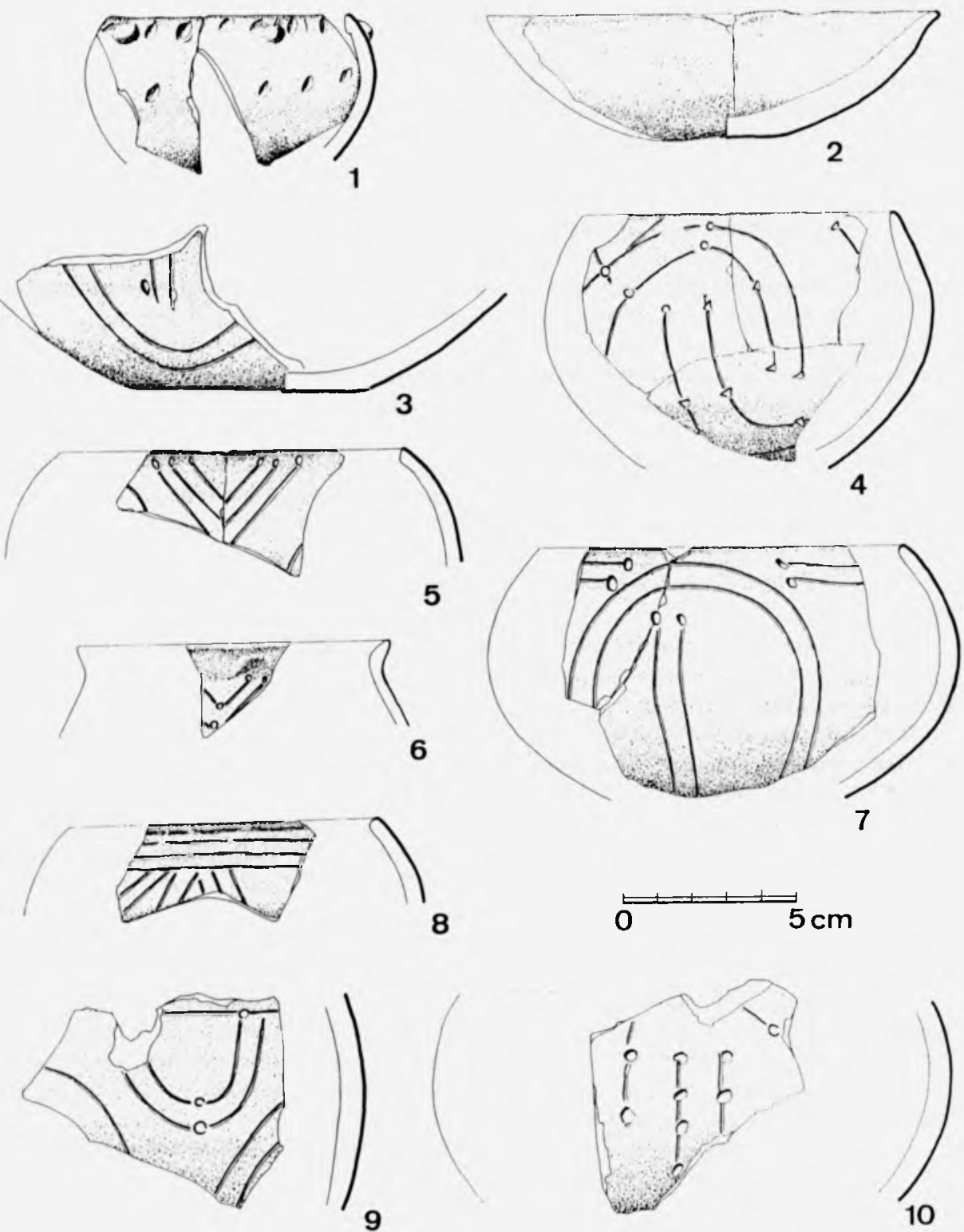

Ryc. 7. Lipnica, gm. Szamotuły, woj. wielkopolskie, stan. 21. Wybór ceramiki z obiektu 25 (rys. J. Sawicka)

Abb. 7. Lipnica, Gem. Szamotuły, Woi. Wielkopolskie, Fst. 21. Keramikauswahl aus Objekt 25 (Zeichn. J. Sawicka)

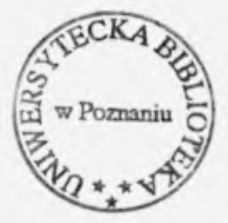




\section{BIBLIOGRAFIA}

Baumann W.

1976 Funde figürlicher Darstellungen der Bandkeramik aus Sachsen, „Jahresschrift für Mitteldeutsche Vorgeschichte" Jg. 60, s. 97-107.

Cehak H.

1933 Plastyka eneolitycznej kultury ceramiki malowanej w Polsce [Rés.: L'Art plastique dans la culture énéolithique de la céramique peinte en Pologne], „Światowit” t. XIV, s. 164252.

Czerniak L.

1994 Wczesny i środkowy okres neolitu na Kujawach 5400-3650 p.n.e. [Sum.: Early and middle period of the Neolithic in Kuiavia], Poznan.

Gediga B.

1970 Motywy figuralne w sztuce ludności kultury lużyckiej [Sum.: Figure motifs in the art of the people of Lusatian culture], Wroclaw - Warszawa - Kraków.

Gleń E., Kaczanowski K.

1974 Próba oceny typu antropologicznego figurki znalezionej na stanowisku Kraków-Pleszów [Sum.: An attempt to identify the anthropological type of the figurine found on the site of Kraków-Pleszów], „Sprawozdania Archeologiczne” t. XXVIII, s. 77-78.

Hoffmann E.

1963 Die Kultur der Bandkeramik in Sachsen, Berlin.

Höckmann $\mathrm{O}$.

1965 Menschliche Darstellungen in der bandkeramischen Kultur, ,Jahrbuch des Römisch-Germanischen Zentralmuseums Mainz" Jg. 12, s. 1-34.

„Informator Archeologiczny”.

1985 Badania. Rok 1984, Warszawa.

1986 Badania. Rok 1985, Warszawa.

1987 Badania. Rok 1986, Warszawa.

Jankowska H., Wojciechowska D.

1973 Figurka antropomorficzna $z$ Wroctawia-Księża Wielkiego [Sum.: The anthropomorphic figurine of Wrocław-Księże Wielkie], „Silesia Antiqua” t. XV, s. 117-131.

Kaufmann D.

1976 Wirtschaft und Kultur der Stichbandkeramiker im Saalegebiet, Berlin.

Kostrzewski J.

1948 Od mezolitu do okresu wędrówek ludów, (w:) Prehistoria ziem polskich, Kraków, s. 118-360.

Majewski K.

1938 Plastyka terrakotowa kultury ceramiki malowanej w zbiorach lwowskich [Zus.: Die Ton-plastik der Kultur der bemalten Keramik in den Sammlungen in Lwów], „Światowit” t. XVII, s. 63-88.

1947 Studia nad kulturq trypilska, „Archeologia" t. I, s. 93-138.

1971 Idole cykladzkie w nowszych badaniach (1935-1970) [Sum.: Cycladic idols in more recent research (1935-1970)], „Archeologia” t. XXII, s. 3-41.

Marešová $\mathrm{K}$.

1972 Neolitická plastika na Moravé, [Zus.: Neolithische Plastik in Māhren], „Časopis Moravského Muzea" t. 46, s. 53-78.

Podborský V.

1985 Těsetice-Kvjovice 2. Figurálni plastika lidu s moravskou malovanou keramikou [Zus.: Těšetice-Kyjovice II - Die figurale Plastik des Volkes mit Mährischer bemalter Keramik], Brno.

Rachwaniec A.

1975 Antropomorficzna glowka gliniana z Nowej Huty-Pleszowa [Sum.: An anthropomorphic head of clay from Nowa Huta-Pleszów], „Sprawozdania Archeologiczne” t. XXVIII, s. 63-76. 
Romanow J.

1977 Trapezowate budowle naziemne ludności kultury ceramiki wstegowej klutej na Dolnym Śląsku [Rés.: Les constructions trapézoïdes „,surterraines” de la population de culture de la céramique rubannée poinçonnée en Basse-Silésie], „Silesia Antiqua” t. XIX, s. 27-55.

Rook E.

1980 Osadnictwo neolityczne w jaskiniach Wyżny Krakowsko-Częstochowskiej [Rés.: Etude sur l'habitat néolithique dans les grottes du Plateau de Cracovie-Częstochowa], ,Materiały Archeologiczne" t. XX, s. 5-114.

Seger $\mathrm{H}$.

1916 Die keramischen Stilarten der jüngeren Steinzeit Schlesiens, „Schlesiens Vorzeit in Bild und Schrift" Neue Folge, Jg. 7, s. 1-89.

Wojciechowski W., Cholewa P.

1995 Osady najwcześniejszych rolników i hodowców na stanowisku 16 w Strzelinie [Zus.: Siedlungen der ältesten Bauern und Tierzüchter Strzelin/Strehlen. Grabungstelle Nr.16], „Studia Archeologiczne" t. XXVII, Wrocław.

\section{FRÜHNEOLITHISCHE ANTHROPOMORPHE FIGÜRCHEN AM BEISPIEL EINES NEUFUNDES AUS LIPNICA, WOI. WIELKOPOLSKIE}

\section{Zusammenfassung}

Wahrend der Ausgrabungen in Lipnica (Fst. 21), Woi. Wielkopolskie (Abb. 1), an der Gasleitungstrasse wurde in einer Grube der Linienbandkeramik (Abb. 2,3) ein anthropomorphes Figürchenfragment aus Ton gefunden. Es ist die untere Partie mit zwei Extremitäten erhalten, wovon eine (die rechte) gänzlich (Abb. 4, I), von der anderen (linken) nur der Unterschenkel erhalten ist (Abb. 4,2). Beide Teile des Figürchens waren wahrscheinlich bemalt und tragen weiterhin ein Ornament aus senkrecht eingeritzten Strichen.

Das Figurche war aus feinem, einigermaßen fetten und sorgfältig bearbeiteten Ton hergestellt, welcher mit einer mineralischen Beimengung von feinkörnigem Grus und Sand gemagert war.

Die kompositorisch-formalen Eigenheiten lassen vermuten, daß es sich um eine vollplastische und frei stehende menschliche Gestalt handelte, welche, wie allgemein üblich zu dieser Zeit, verhältnismäßig realistisch und dem Anschein nach frei von steatopygischen Zügen war, mit einzeln modellierten Beinen. Die Größenrekonstruktion des Figürchens ergab etwa $20-30 \mathrm{~cm}$ (Abb. 5). Ihre Funktion erfüllte sie sicher als frühneolithisches Idol oder als Spielzeug.

Zum Fund von Lipnica gibt es keine enge Analogie. Aufgrund der morphologischen und vergleichenden Analyse ist er zwar den figuralen Konventionen der mitteleuropäischen Welt der Bandkeramik (Niederschlesien, Deutschland) sehr nahestehend, jedoch spiegelt er durch die Bemalung gleichfalls Impulse aus dem südostlichen Bandkeramikkreis (Ukraine, Moldavien) wider.

Die Datierung des Figürchens erfolgt vor allem auf der Grundlage der begleitenden (Objekt 25) Gefäßkeramik (Morphologie und Verzierung) in die sogenannte Notenphase (II) der Linienbandkeramik im polnischen Tiefland (Abb. 6; 7). 